\title{
Fulani show decreased susceptibility to Plasmodium falciparum infection versus Mossi: data from a community-wide screening and treatment of asymptomatic carriers in Burkina Faso
}

Alfred B Tiono ${ }^{1 *}$, Sodiomon B Sirima ${ }^{1}$ and Kamal Hamed ${ }^{2}$

\begin{abstract}
Background: The Fulani ethnic group is known to have a lower susceptibility to Plasmodium falciparum infection than the Mossi.

Methods: This commentary describes data from a recent cluster-randomized trial of community-wide screening and treatment of asymptomatic carriers of P. falciparum in 18 villages in Saponé, Burkina Faso.

Results: The Fulani groups had a lower proportion of asymptomatic carriers at any occasion, a lower density of asexual forms and gametocytes of $P$. falciparum at baseline, and, in children under five years of age, lower rates of symptomatic malaria episodes per person-year than the Mossi.
\end{abstract}

Discussion and conclusion: These data confirm previously reported differences in $P$. falciparum susceptibility between Fulani and Mossi.

Keywords: Malaria, Plasmodium falciparum, Mossi, Fulani, Artemether-lumefantrine

\section{Background and methods}

Recent investigations into the ethnic susceptibility of Fulani and Mossi for Plasmodium falciparium infection have consistently reported that Fulani have a lower susceptibility than Mossi [1-5]. A recent clusterrandomized trial in 18 villages in Saponé, Burkina Faso, which investigated the systematic, community-wide screening and treatment of asymptomatic carriers of P. falciparum with artemether-lumefantrine (AL) [6], provided further data on the susceptibility differences between these two ethnic groups. This trial enrolled a combined majority of Fulani and Mossi subjects and assessed the incidence of microscopy-confirmed asymptomatic carriage, asexual forms and gametocytes, as well as 'symptomatic malaria episodes including fever and a

\footnotetext{
* Correspondence: t.alfred@fasonet.bf

'Centre National de Recherche et de Formation sur le Paludisme, Ministère de la Santé, 01 BP 2208, Ouagadougou, Burkina Faso

Full list of author information is available at the end of the article
}

parasite density $>5,000 / \mu l$ ' (abbreviated as SMRC5000 throughout the text) at various time points over the 12month study [6].

While the exact biological reason for the lower susceptibility to P. falciparum of Fulani compared with Mossi is not fully understood, it is known that it is not due to an increased frequency of classic malaria-resistance genes, such as haemoglobin $S$, haemoglobin $C$, -alpha 3.7 deletional thalassaemia, G6PDA-, and HLA B*5301 [7]. However, Fulani have been shown to have higher levels of antibodies against two $P$. falciparum antigens [3] and stronger malaria-specific IgG, IgG1, IgG3 and IgM responses [8].

Further investigations into immunological differences that may affect susceptibility to $P$. falciparum have centred on FcyRIIa genotypes that affect the binding of different IgG subclasses. The FcyRIIa-H/H131 genotype is associated with higher levels of anti-malarial IgG2 and IgG3 antibodies, while the FcyRIIa-R/R131 genotype is 
associated with higher levels of IgG1 antibodies $[9,10]$. Individuals with the $\mathrm{R}$ allele of FcyRIIa have higher antibody levels than those with the $\mathrm{H}$ allele [11]. The FcyRIIa-H/H131 genotype and $\mathrm{H} 131$ allele are reported to exist at higher frequencies in the Fulani ethnic group [10]. However, there is a similar distribution of FcyRIIaR131H polymorphism in Fulani and Mossi [11]. Overall, Fulani have higher antibody levels than Mossi [11]. Additionally, in Fulani, it is known that the IL4-524 T allele, which codes for the Th2 cytokine interleukin-4, is at high frequency and is associated with elevated antibody levels against malarial antigens [12]. A functional deficit of $\mathrm{T}$ regulatory cells may also contribute to Fulani having a higher resistance to malaria [4].

It has also been demonstrated that parasitaemia in asymptomatic Fulani is more common in individuals with lactase non-persistence genotypes (lactose intolerance), although this difference was not statistically significant [5]. This suggests that the potential immunoprotective properties of dietary cow's milk may contribute to the partial malaria resistance of Fulani, yet this requires further investigation [5].

This commentary describes differences in susceptibility to $P$. falciparum infection between Fulani and Mossi subjects in the above-mentioned study [6].

\section{Ethics section}

The protocol and the informed consent form were reviewed and approved by the Institutional Review Board of the Centre National de Recherche et de Formation sur le Paludisme and by the National Ethical Committee for Health Research of Burkina Faso. Prior to study initiation, a community meeting was held in each of the selected clusters to discuss the study with the community. The freedom of each individual household and a household member to decide on participation was discussed to minimize the potential influence of key opinion leaders in each cluster. Individual informed consent was obtained from each participant during a visit to the household before any study procedure.

\section{Results}

\section{Baseline characteristics}

In total, 14,075 subjects aged between one month and 104 years were enrolled. The intervention arm included 6,817 subjects with a mean age of 24.1 years, of whom $46.4 \%$ were male, $90.6 \%$ were Mossi and 8.7\% were Fulani. The control arm included 7,258 subjects with a mean age of 23.4 years, of whom 47.4\% were male, $95.7 \%$ were Mossi and $3.8 \%$ were Fulani. The intervention and control arms had similar proportions of children less than five years of age (17.0\% and $15.6 \%$, respectively).

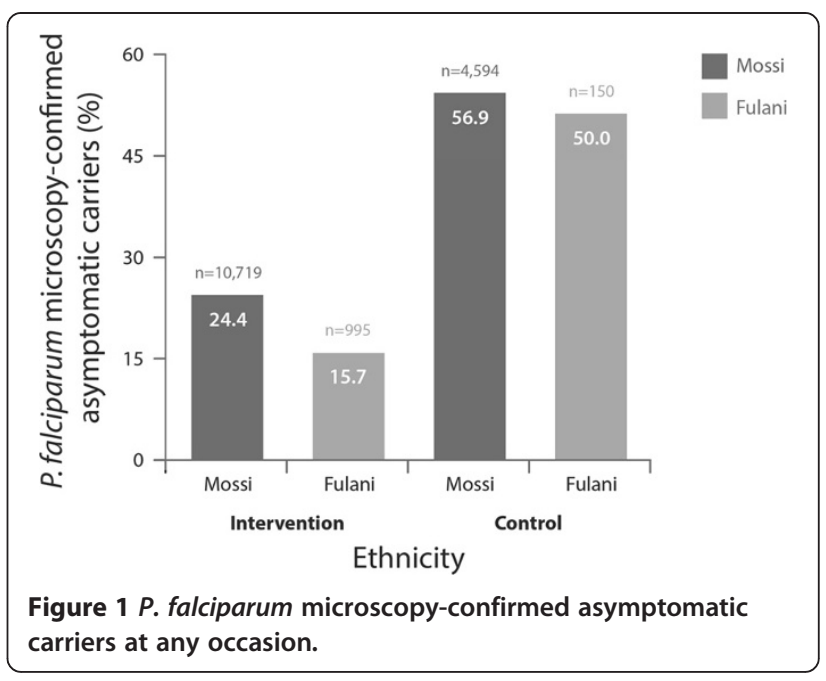

Plasmodium falciparum infection rates by ethnicity Proportions of asymptomatic carriers

The Fulani groups had a lower proportion of microscopyconfirmed asymptomatic carriers than the Mossi groups at any occasion (Figure 1). Subjects may have been counted multiple times if diagnosed as asymptomatic carriers more than once during the study.

\section{Parasite densities (asexual forms and gametocytes)}

The Fulani groups had lower densities of microscopyconfirmed P. falciparum asexual forms (Figure 2) and gametocytes (Figure 3) than the Mossi groups at baseline.

\section{Incidence of SMRC5000}

In children under five years of age, the Fulani groups had lower rates of SMRC5000 per person-year than the Mossi groups at follow-up (Table 1). However, when the analysis included subjects of all ages, the Fulani groups

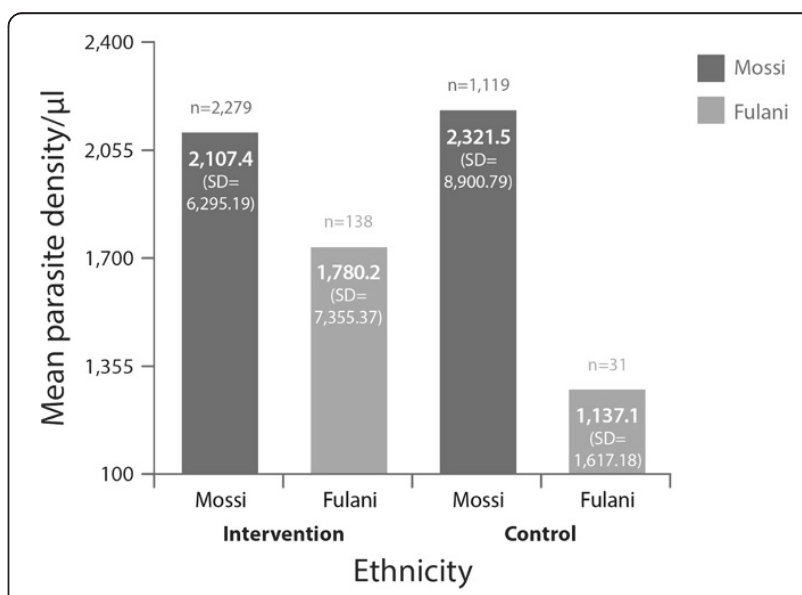

Figure 2 Density of $P$. falciparum asexual forms by microscopy at baseline. 


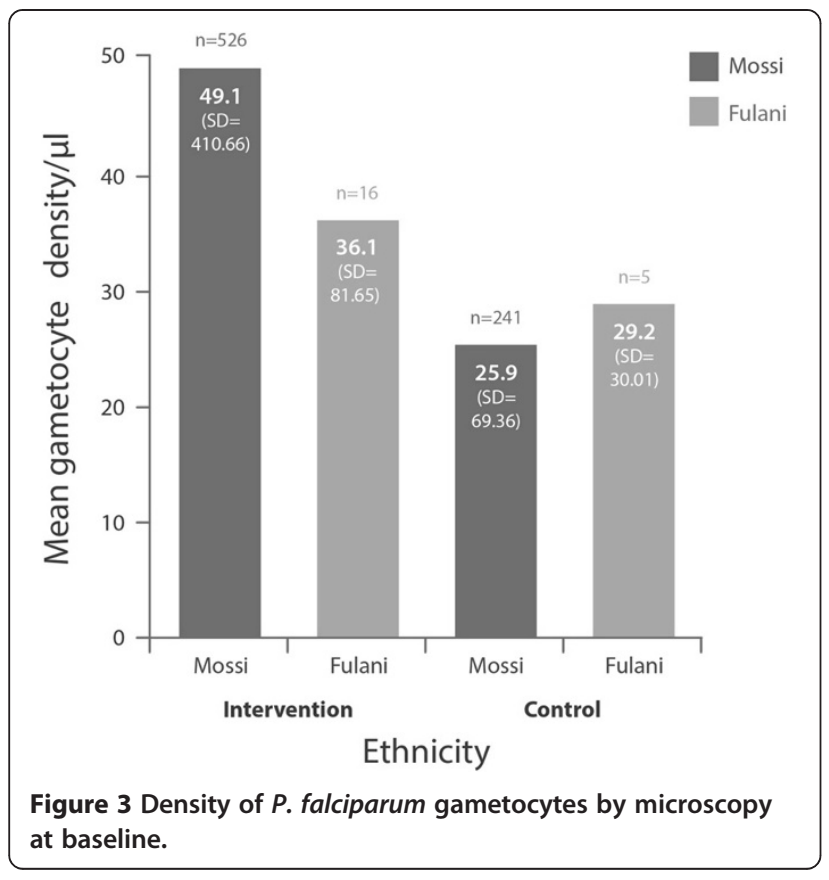

had higher rates of SMRC5000 per person-year than the Mossi groups (Table 2).

\section{Discussion}

Demographic surveillance data for the district show the distribution of Fulani and Mossi in the area as 7.1\% and $90.7 \%$, respectively. The proportions of each group enrolled in the study are generally consistent with this $(8.7 \%$ and $90.6 \%$ in the intervention arm, $3.8 \%$ and $95.7 \%$ in the control arm).

The data we present confirm previously reported differences in susceptibility to $P$. falciparum malaria between Fulani and Mossi ethnic groups [1-5]. There was a consistently reduced incidence of the indicators for $P$. falciparum infection in Fulani over Mossi (Figures 1, 2 and 3 and Table 1), except for a reversal of this trend in the rates of SMRC5000 per person-year in subjects of all ages at follow-up (all subjects diagnosed at any time for asymptomatic carriage, Table 2).

Table 1 SMRC5000* per person-year in infants and children (under five years) at follow-up (all subjects diagnosed at any time with asymptomatic carriage)

\begin{tabular}{lllll}
\hline Study arm & Ethnicity & $\begin{array}{l}\text { Number of } \\
\text { SMRC5000 }\end{array}$ & $\begin{array}{l}\text { Person-year } \\
\text { observed }\end{array}$ & $\begin{array}{l}\text { SMRC5000 per } \\
\text { person-year }\end{array}$ \\
\hline $\begin{array}{l}\text { Intervention } \\
(\mathbf{n}=\mathbf{5 1 2})\end{array}$ & Mossi & 384 & 350.6 & 1.10 \\
\cline { 2 - 5 } & Fulani & 31 & 32.8 & 0.95 \\
\hline $\begin{array}{l}\text { Control } \\
\text { (n= 203) }\end{array}$ & Mossi & 154 & 149.1 & 1.03 \\
\cline { 2 - 5 } & Fulani & 7 & 9.3 & 0.76 \\
\hline
\end{tabular}

* SMRC5000 = Symptomatic malaria episodes including fever and a parasite density $>5,000 / \mu \mathrm{l}$.
Table 2 SMRC5000* per person-year in subjects of all ages at follow-up (all subjects diagnosed at any time with asymptomatic carriage)

\begin{tabular}{lllll}
\hline Study arm & Ethnicity & $\begin{array}{l}\text { Number of } \\
\text { SMRC5000 }\end{array}$ & $\begin{array}{l}\text { Person-year } \\
\text { observed }\end{array}$ & $\begin{array}{l}\text { SMRC5000 per } \\
\text { person-year }\end{array}$ \\
\hline $\begin{array}{l}\text { Intervention } \\
(\mathbf{n}=\mathbf{2 , 7 4 0 )}\end{array}$ & Mossi & 722 & 1928.1 & 0.37 \\
\cline { 2 - 5 } & Fulani & 57 & 116.8 & 0.49 \\
\hline $\begin{array}{l}\text { Control } \\
(\mathbf{n}=\mathbf{1 , 3 8 1 )}\end{array}$ & Mossi & 257 & 1024.2 & 0.25 \\
\cline { 2 - 5 } & Fulani & 14 & 29.2 & 0.48 \\
\hline
\end{tabular}

* SMRC5000 = Symptomatic malaria episodes including fever and a parasite density $>5,000 / \mu \mathrm{l}$.

This inconsistency in SMRC5000 per person-year in infants and children (under five years) and in subjects of all ages at follow-up (Tables 1 and 2) was unanticipated. One possible reason for this may be that treatment of asymptomatic carriers with artemisinin-based therapy may increase subsequent susceptibility to symptomatic malaria more in adult Fulani who are known to have stronger immune responses to malaria than in Mossi.

Therefore, areas for further research include a more detailed assessment of differences in SMRC5000 (per person-year) between children and adults and any biological reasons for these differences, as well as investigations into potential interethnic differences in the effect of artemisinin derivatives on naturally acquired protective immunity. Other beneficial studies may assess intraFulani susceptibility distribution, which may correlate with previously reported differences in anti-malarial antibody levels amongst the Fulani themselves [12].

\section{Conclusion}

Data from the systematic, community-wide screening and treatment of asymptomatic carriers of $P$. falciparum with artemether-lumefantrine (AL) [6] confirm previously reported differences in P. falciparum susceptibility between Fulani and Mossi.

\section{Abbreviations \\ SMRC5000: Symptomatic malaria episodes including fever and a parasite density $>5,000 / \mu l$.}

\section{Competing interests}

AT has received honoraria from Novartis Pharma AG, Basel, Switzerland to attend Advisory Board meetings to discuss this study. $\mathrm{KH}$ is an employee of Novartis Pharmaceuticals Corporation. SS has declared no competing interests.

\section{Authors' contributions}

All authors were involved in the design of the primary study and defining the content for, writing and critically reviewing this manuscript. AT and SS were involved in data collection, while AT and $\mathrm{KH}$ conducted the data analysis. All authors had full access to data in the study, discussed the results, reviewed the draft manuscript and agreed on the final version. AT had final responsibility for the decision to submit the manuscript for publication. Editorial assistance was provided by PreScript Communications, with funding from Novartis Pharma AG. 


\section{Author details}

'Centre National de Recherche et de Formation sur le Paludisme, Ministère de la Santé, 01 BP 2208, Ouagadougou, Burkina Faso. ${ }^{2}$ Novartis

Pharmaceuticals Corporation, One Health Plaza, East Hanover, NJ 07936-1080, USA.

Received: 23 January 2013 Accepted: 14 May 2013

Published: 16 May 2013

\section{References}

1. Modiano D, Petrarca V, Sirima BS, Bosman A, Nebie I, Diallo D, Lamizana L, Esposito F, Coluzzi M: Plasmodium falciparum malaria in sympatric ethnic groups of Burkina Faso, west Africa. Parassitologia 1995, 37:255-259.

2. Modiano D, Petrarca V, Sirima BS, Nebie I, Diallo D, Esposito F, Coluzzi M: Different response to Plasmodium falciparum malaria in west African sympatric ethnic groups. Proc Natl Acad Sci USA 1996, 93:13206-13211.

3. Modiano D, Chiucchiuini A, Petrarca V, Sirima BS, Luoni G, Perlmann H, Esposito F, Coluzzi M: Humoral response to Plasmodium falciparum Pf155/ ring-infected erythrocyte surface antigen and Pf332 in three sympatric ethnic groups of Burkina Faso. AmJTrop Med Hyg 1998, 58:220-224.

4. Torcia MG, Santarlasci V, Cosmi L, Clemente A, Maggi L, Mangano VD, Verra F, Bancone G, Nebie I, Sirima BS, Liotta F, Frosali F, Angeli R, Severini C Sannella AR, Bonini P, Lucibello M, Maggi E, Garaci E, Coluzzi M, Cozzolino F, Annunziato F, Romagnani S, Modiano D: Functional deficit of T regulatory cells in Fulani, an ethnic group with low susceptibility to Plasmodium falciparum malaria. Proc Natl Acad Sci USA 2008, 105:646-651.

5. Lokki Al, Jarvela I, Israelsson E, Maiga B, Troye-Blomberg M, Dolo A, Doumbo OK, Meri S, Holmberg V: Lactase persistence genotypes and malaria susceptibility in Fulani of Mali. Malar J 2011, 10:9.

6. Tiono AB, Ouedraogo A, Ogutu B, Diarra A, Coulibaly B, Gansane A, Sirima SB, O'Neil G, Mukhopadhyay A, Hamed K: A controlled, parallel, clusterrandomized trial of community-wide screening and treatment of asymptomatic carriers of Plasmodium falciparum in Burkina Faso. Malar J 2013, 12:79.

7. Modiano D, Luoni G, Sirima BS, Lanfrancotti A, Petrarca V, Cruciani F, Simpore J, Ciminelli BM, Foglietta E, Grisanti P, Bianco I, Modiano G, Coluzzi M: The lower susceptibility to Plasmodium falciparum malaria of Fulani of Burkina Faso (west Africa) is associated with low frequencies of classic malaria-resistance genes. Trans R Soc Trop Med Hyg 2001, 95:149-152.

8. Farouk SE, Dolo A, Bereczky S, Kouriba B, Maiga B, Farnert A, Perlmann H, Hayano M, Montgomery SM, Doumbo OK, Troye-Blomberg M: Different antibody- and cytokine-mediated responses to Plasmodium falciparum parasite in two sympatric ethnic tribes living in Mali. Microbes Infect 2005, 7:110-117.

9. Israelsson E, Vafa M, Maiga B, Lysen A, Iriemenam NC, Dolo A, Doumbo OK, Troye-Blomberg M, Berzins K: Differences in Fcgamma receptor lla genotypes and lgG subclass pattern of anti-malarial antibodies between sympatric ethnic groups in Mali. Malar J 2008, 7:175.

10. Nasr A, Iriemenam NC, Giha HA, Balogun HA, Anders RF, Troye-Blomberg M, Elghazali G, Berzins K: FcgammaRlla (CD32) polymorphism and antimalarial IgG subclass pattern among Fulani and sympatric ethnic groups living in eastern Sudan. Malar J 2009, 8:43.

11. Cherif MK, Sanou GS, Maiga B, Israelsson E, Ouedraogo AL, Bougouma EC, Diarra A, Ouedraogo A, Ouattara AS, Troye-Blomberg M, Dolo A, Cavanagh DR, Theisen M, Modiano D, Sirima SB, Nebie I: FcgammaRlla polymorphism and anti-malaria-specific $\lg G$ and $\lg G$ subclass responses in populations differing in susceptibility to malaria in Burkina Faso. Scand I Immunol 2012, 75:606-613.

12. Luoni G, Verra F, Arca B, Sirima BS, Troye-Blomberg M, Coluzzi M, Kwiatkowski D, Modiano D: Antimalarial antibody levels and IL4 polymorphism in the Fulani of West Africa. Genes Immun 2001, 2:411-414.

\section{doi:10.1186/1475-2875-12-163}

Cite this article as: Tiono et al:: Fulani show decreased susceptibility to Plasmodium falciparum infection versus Mossi: data from a communitywide screening and treatment of asymptomatic carriers in Burkina Faso. Malaria Journal 2013 12:163.

\section{Submit your next manuscript to BioMed Central and take full advantage of:}

- Convenient online submission

- Thorough peer review

- No space constraints or color figure charges

- Immediate publication on acceptance

- Inclusion in PubMed, CAS, Scopus and Google Scholar

- Research which is freely available for redistribution
C Biomed Central 